\title{
Anti-smoking advertising campaigns targeting youth: case studies from USA and Canada
}

\author{
Cornelia Pechmann, Ellen Thomas Reibling
}

\begin{abstract}
Objective-To assist in planning antismoking advertising that targets youth. Using five US state campaigns, one US research study, and a Canadian initiative as exemplars, an attempt is made to explain why certain advertising campaigns have been more cost effective than others in terms of reducing adolescent smoking prevalence. Several factors which prior research and theory suggest may be important to cost effectiveness are examined. Specifically, three variables pertaining to the advertising message (content, consistency, and clarity) and two variables related to the advertising execution or style (age of spokesperson and depiction of smoking behaviour) are studied.
\end{abstract}

Design-A case study approach has been combined with supplemental data collection and analysis. To assess campaign effects, published articles and surveys of adolescent smoking prevalence in campaign versus control (non-campaign) locations were utilised. Adolescent subjects provided supplemental data on the advertising message variables. Trained adults content analysed each advertisement to assess the executional variables.

Subjects-A total of 1128 seventh grade (age 12-13 years) and 10th grade (age 15-16 years) students participated in the supplemental data collection effort.

Results-An anti-smoking advertising campaign initiated by Vermont researchers was found to be the most cost effective in that it significantly reduced adolescent smoking prevalence at a low per capita cost. Next in order of cost effectiveness were California, Massachusetts, and Florida because behavioural outcomes were inconsistent across time and/or grades. California was ranked higher than the other two because it spent less per capita. Minnesota and Canada were ineffective at reducing adolescent smoking prevalence, and no comparison outcome data were available for Arizona. Four factors were found to be associated with increased cost effectiveness: (1) a greater use of message content that prior research suggests is efficacious with youth; (2) a more concentrated use of a single efficacious message; (3) an avoidance of unclear messages; and (4) an increased use of youthful spokespeople that adolescents could more readily identify with. No indication was found that depictions of smoking undermined campaign effectiveness by inadvertently implying that smoking was prevalent.

Conclusions-The highly cost effective Vermont campaign can be used as a model for future efforts. It is estimated that $79 \%$ of the Vermont advertisements conveyed efficacious messages, $58 \%$ concentrated on a single efficacious message, $70 \%$ showed youthful spokespeople, and only $4 \%$ contained unclear messages. The results suggest that, in the less effective campaigns, as few as $\mathbf{2 5 \%}$ of the advertisements contained messages that prior research indicates should be efficacious with youth, as few as $10 \%$ of the advertisements focused on one efficacious message, and up to $32 \%$ of the advertisements lacked clearcut messages.

(Tobacco Control 2000;9(Suppl II):ii18-ii31)

Keywords: anti-smoking advertising campaigns; youth targeted advertising; cost effectiveness

Legislators and public health officials in the USA are currently debating the expenditure of millions of dollars flowing into their state coffers from the national tobacco settlement. In these debates, it should be recognised that anti-smoking advertising has the potential to be a viable and cost effective deterrent to youth smoking. When the Fairness Doctrine was applied to tobacco related broadcast speech from 1967 to 1970, broadcasters were required to donate an estimated $\$ 298$ million per year (in 1996 dollars) in free airtime for anti-smoking advertising messages. Research indicates that per capita cigarette consumption, and both adult and adolescent smoking prevalences, fell significantly during this period..$^{1-5}$

More recently, controlled experiments comparing "test" (intervention) and "control" (non-intervention) communities found that anti-smoking advertising can significantly reduce youth smoking prevalence, particularly when combined with synergistic school and community based activities. ${ }^{6-8}$ Additional supportive evidence comes from controlled laboratory experiments in which adolescents have been exposed either to anti-smoking or control (smoking unrelated) advertisements, and then asked to complete surveys that assessed their smoking related knowledge, perceptions, and behavioural intentions. Middle school students who viewed anti-smoking (versus control) advertising reported significantly less favourable perceptions of smokers. ${ }^{9}$ 
Likewise, showing an anti-smoking advertisement before a feature film significantly diluted the impact of the film's pro-smoking imagery on high school students. ${ }^{10}$

These prior studies indicate that antismoking advertising can work well under fairly controlled circumstances. However, like other advertising, it carries no guarantees. Indeed, several tobacco use prevention media campaigns have been documented failures because of inadequate length, funding or other factors. ${ }^{11-14}$ Officials planning anti-smoking advertising are faced with an array of challenging planning and implementation tasks. The goal of this study is to provide guidance in planning effective anti-smoking advertising campaigns targeting youth, based on an analysis of past campaigns initiated by five US states (Arizona, California, Florida, Massachusetts, and Minnesota), a different country (Canada), and researchers from the University of Vermont who initiated a multicommunity trial.

\section{Overview of study}

The current study is an offshoot of work that we conducted in 1997-98 on adolescents' impressions of anti-smoking advertisements. ${ }^{15}$ At that time, we obtained copies of all English language television advertisements that had been used in major North American anti-smoking campaigns from 1985 to 1997. All campaigns had identified adolescents as either a primary or sole target audience. In total, we obtained 167 advertisements from six of the campaigns listed above. The Florida initiative had not yet started. We arranged for each advertisement to be viewed by approximately 50 adolescents, half seventh graders (age 12-13 years), half 10th graders (age 15-16 years). The adolescents then completed surveys that were designed to assess each advertisement's message content, the level of agreement (clarity) or disagreement (confusion) over the message content, and the consistency of messages within a campaign (that is, the proportions of advertisements containing the same message). In addition, adults content analysed each advertisement to determine whether the spokesperson appeared to be youthful (under 25 years old) and whether smoking behaviour was depicted. Prior research had indicated that these variables might potentially influence the effectiveness of anti-smoking advertisements targeting youths. ${ }^{16-18}$

We found that the campaigns differed rather substantially on the advertising message variables (content, clarity, and consistency) and on the executional variables (youthful spokespeople and depictions of smoking). We believed that, based on published reports or data, we could determine which campaigns had been relatively more effective than others at reducing adolescent smoking prevalence. Campaign costs could also be assessed. Hence, we decided to embark on a study to examine whether higher rankings on any of the advertising variables seemed to be associated with greater cost effectiveness. We were able to identify several factors that appeared to improve campaign cost effectiveness as measured by significant reductions in adolescent smoking prevalence. We present our study below, beginning with an explanation of the advertising variables and tentative research hypotheses, followed by our method and findings, and ending with a discussion of limitations and implications.

\section{Advertising variables studied because possible associations with cost effectiveness}

MESSAGE CONTENT

In our initial 1997-98 study, ${ }^{15}$ we reviewed the anti-smoking advertisements that had been provided by campaign sponsors and developed a checklist of messages used. As our adolescent subjects viewed each advertisement, they placed a checkmark next to each message they felt it contained. If $80 \%$ or more of the adolescents agreed that an advertisement contained a message, it was put into that message category. Categories with 12 or more advertisements were formally labelled. We identified seven such mutually exclusive categories. These categories are listed below.

- Long term effects-advertisements that discuss the long term health effects of smoking, such as cancer and lung disease.

- Short term effects-advertisements that highlight the short term cosmetic effects of smoking, such as smelly breath, and related outcomes such as romantic rejection.

- Marketing practices-advertisements that describe relatively innocuous tobacco marketing practices, such as the use of glamorous models and the distribution of free promotional items.

- Deceptive portrayal of lethal productadvertisements that highlight the deceptive tactics used to sell what is essentially a lethal and addictive product, such as illegally targeting minors and falsely claiming that cigarettes are nonaddictive.

- Second hand smoke-advertisements that stress the negative impact of second hand smoke on family members and other people, particularly infants and children.

- Smoker as negative role modeladvertisements that depict smokers as people who have unwisely chosen a lifestyle that is both unappealing and unhealthy.

- Refusal skills-advertisements that feature attractive, personable individuals and show these individuals refusing to smoke.

We relied on prior research to assess the potential efficacy of each message in terms of dissuading adolescents from smoking. ${ }^{15}$ In our own research, hundreds of adolescents were randomly assigned to view advertisements of a particular type and the effects of this exposure (versus exposure to unrelated-to-smoking or control messages) on intentions to smoke were statistically assessed. ${ }^{15}$ Another study examined the transcripts of innumerable focus groups that were convened to evaluate anti-smoking advertisements and looked for consensus as to which advertisements seemed to be the most convincing. ${ }^{19}$ 
Both studies concluded that second hand smoke messages work well with adolescents. ${ }^{15}{ }^{19}$ In addition, the focus group study found that youths responded well to advertisements disclosing the deception used to sell what is essentially a lethal and addictive product. ${ }^{19}$ Finally, our own experimental study indicated that adolescents were persuaded by social norm appeals, meaning advertisements that portrayed a smoker's lifestyle negatively (as unappealing and unhealthy) or advertisements that showed attractive people refusing to smoke. Other messages were found to be relatively ineffective with adolescents, including those stressing long term effects only, ${ }^{15}{ }^{19}$ short term effects only, ${ }^{15}$ or relatively innocuous tobacco marketing practices. ${ }^{15}$ Thus, for the current study, we tentatively predicted that the more cost effective prevention campaigns would make greater use of the following messages: deceptive portrayal of lethal product, second hand smoke, smoker as negative role model, and/or refusal skills.

MESSAGE CONSISTENCY

Advertising for most products and services is designed to communicate a single persuasive message for an extended period of time (for example, Crest fights cavities, Listerine kills germs). ${ }^{20-22}$ The goal is to remind consumers continually of the brand name and its unique selling proposition (positioning) such that, when making consumption or purchase decisions, consumers will immediately think of the brand and remember why to choose it. Also, consumers frequently do not attend to or process advertisements because they are busy or distracted. ${ }^{22}$ Hence, advertisers rely on repetition, the "oft referred to soul of persuasion" to increase the likelihood of changing behaviour. $^{23}$ To avoid boring or irritating consumers with repetitive information, advertisers use multiple advertisement executions, that is, variations on the theme (such as different settings). ${ }^{22}$

Message repetition or consistency should be beneficial for anti-smoking advertising as well. If a campaign has a large budget, it perhaps has more flexibility in terms of conveying multiple messages. However, even cigarette advertisers with substantial budgets tend to utilise single themes. The Marlboro Man (male autonomy) and Virginia Slims (liberated female) campaigns are just two examples of this. ${ }^{24}$ Therefore, we tentatively predicted that an anti-smoking campaign's cost effectiveness would be enhanced by a focus on a single efficacious theme.

MESSAGE CLARITY

In consumer advertising, it is widely recognised that messages can be either poorly comprehended or mistakenly comprehended. ${ }^{25} 26$ Despite advertisers' best efforts, consumers frequently misunderstand the specific claims that are made, the general conclusions reached, and/or the sponsors of the advertisements. ${ }^{27}{ }^{28}$ Hence, it is commonplace for advertisers to test consumers' comprehension of advertisements in rough cut and/or final form, to rectify any problems that might arise. ${ }^{18}{ }^{29}$ Subtle changes in wording or dramatisation can make a substantial difference in whether a message is generally understood by target audience members.

There are some who believe that people can be subliminally persuaded by advertisements, independent of message awareness or comprehension. ${ }^{30}$ However, numerous studies by psychologists and consumer researchers have found no link between subliminal messages and consumer behaviour. It appears that subliminal advertising simply does not have the power attributed to it by its advocates. $^{31}$ As one advertising agency executive put it, "We have enough trouble persuading consumers using a series of up front 30 second advertisements-how could we do it in $1 / 300$ th of a second?". ${ }^{21}$ The rare instances of documented subliminal advertising effects have been produced in highly contrived and artificial settings that have little relevance to marketers. ${ }^{22} 32$

Anti-smoking messages can be quite complex-for example, those that argue that tobacco marketers use deception to sell a deadly and addictive product. If youths fail to understand what an advertisement is saying, it is unlikely to have the intended effects. At least one study found that an anti-smoking advertisement that was carefully crafted by adult professionals, but subtle in its approach rather than hard hitting, was poorly understood by the adolescents for whom it was intended. ${ }^{33}$ Hence, we predicted that anti-smoking campaigns with a higher proportion of readily comprehended and strong messages would tend to be more cost effective.

AGE OF SPOKESPERSON

In general, people are more likely to be influenced by a persuasive appeal if they perceive it as coming from a spokesperson with whom they feel a sense of similarity. ${ }^{21}$ When audiences identify with a spokesperson, they are more likely to accept that person's opinions and recommendations as credible and relevant to their own lives. ${ }^{22}{ }^{34}$ Advertisers typically try to ensure that target audience members feel a sense of similarity or identification with the spokesperson by using a person that is similar to the audience in age, sex, race and/or lifestyle. ${ }^{16} 17$ 35-37

When advertisers court adolescents, they generally make a concerted effort to use youthful spokespeople who will be believed and respected by the youth subculture. ${ }^{38} 39$ Some cigarette advertisers apparently feel that it is important to use youthful spokespeople as well. ${ }^{17} 38$ According to studies, tobacco advertisers frequently violate their voluntary code to rely on models that look to be at least 25 years old. ${ }^{17}$ One study examined magazines that accept cigarette advertisements and are popular with 12-15 year olds (for example, Sports Illustrated and People) and reported that four out of six cigarette models appeared to be under 25, with the median age being $19 .^{40}$ Adolescents also reportedly prefer younger cigarette models. ${ }^{17}$ Often the implied 
message seems to be that, by smoking, they will become like the attractive young people in the advertisements. ${ }^{36}$ Experts have opined that the Marlboro Man appeals to youth, despite his age, by symbolising autonomy and freedom from authority, two dominant developmental goals for adolescents. ${ }^{35}$

The general rule of thumb is that, when targeting adolescents, spokespeople should be just slightly older than the target group and hence aspirational. ${ }^{38}$ Models can sometimes be too young, because teens are looking for images of "independence, adventure seeking, social approval, and sophistication." 35 Since the advertising campaigns that we analysed targeted a diverse group of youths from roughly 9-19 years old, we could not address the issue of whether some of the spokespeople might have been too young for some audiences. Instead, we tentatively predicted that campaigns that made greater use of youthful spokespeople would be more effective at lowering adolescent smoking prevalence, holding other factors constant. ${ }^{41}$

DEPICTIONS OF SMOKING BEHAVIOUR

We also felt that it was important to consider the use of advertisements that depicted people smoking cigarettes. We were concerned that if a campaign depicted smoking too frequently, it might inadvertently imply that the behaviour is prevalent, normal, and accepted and thus convey a contradictory message. ${ }^{41}{ }^{42}$ Adolescents already overestimate smoking rates among both peers and adults, and the more extreme the overestimate the higher the risk of smoking initiation. ${ }^{43}$ It may sometimes be appropriate to depict smokers to illustrate the negative aspects of tobacco use, model refusal skills, portray tobacco executives or the like. However, many experts feel that depictions of smoking in antismoking advertisements should be minimised because of the potential for unintended adverse effects. ${ }^{18}$

\section{Method}

OVERVIEW

Turning to our research method, we first ranked each focal campaign on each advertising variable that we speculated might be related to cost effectiveness. Next, we obtained data on campaign costs and effects and developed cost effectiveness rankings. Then, we tested our tentative predictions regarding the relation between each advertising variable and cost effectiveness by comparing how the campaigns ranked on each dimension. For instance, we compared how the campaigns ranked in terms of message content versus cost effectiveness. If the rankings seemed to be associated and in the expected direction (for example, positively), we concluded that there was some support for our predictions.

ASSESSMENT OF ADVERTISING VARIABLES

To rank the campaigns on each advertising variable, we relied on the materials submitted by campaign officials. Officials assured us that they provided a complete or virtually complete set of advertisements from 1985 to 1997.
Florida advertisements were not included because we completed this phase of the work in 1998 and their campaign started later. Adolescents provided the data used for ranking each campaign on the message variables: content, clarity, and consistency. We felt that adolescents would be the best judgesparticularly regarding message clarity-of whether the messages would be comprehended by other youths. We believed that the executional variables (use of youthful spokespeople and depictions of smoking) could be readily assessed by adults trained in content analysis so we used that approach.

Data were collected from adolescents as follows. We recruited 1128 seventh and 10th graders in California from middle class, ethnically diverse school districts. ${ }^{15}$ The advertisements from the various sponsors were randomly divided into small pods of 8-9. Each adolescent was randomly assigned to evaluate one pod of advertisements. Immediately after viewing each advertisement twice, subjects answered a series of closed ended questions about the advertisement.

We used the data from adolescents in several ways. To assess the extent to which a campaign employed messages that research suggests may be especially efficacious for youth, we did the following. If at least $80 \%$ of subjects agreed that an advertisement contained a certain message, it was classified into that category (see earlier discussion). Then, for each campaign, we calculated the total percentage of advertisements that fell into the efficacious categories (deceptive portrayal of lethal product, second hand smoke, smoker as negative role model, and refusal skills). Vermont's score on efficacious message content, for instance, was $79 \%$ because $58 \%$ of its advertisements were classified as refusal skills, $13 \%$ as deceptive portrayal of lethal product, and $8 \%$ as smoker as negative role model.

To assess message consistency, we relied on the percentage of advertisements that fell into the most commonly used efficacious category. In the case of Vermont, since the most commonly used efficacious message was refusal skills and 58\% of the advertisements used it, the consistency rating was $58 \%$. To judge message clarity, we relied on the percentage of advertisements rated unclassifiable, meaning that fewer than $80 \%$ of the adolescents could agree on the message conveyed.

Additionally, three trained adults content analysed each advertisement to assess if the spokesperson (main character) appeared to be under 25 years of age and if any person was shown to be smoking cigarettes. ${ }^{36}{ }^{44}$ Inter-rater reliability was $81 \%$. Researchers consider reliabilities over $80 \%$ to be acceptable..$^{45}$ For each campaign, we then computed the percentages of advertisements that contained youthful spokespeople and depicted smoking behaviour.

ANALYSES OF CAMPAIGN COSTS

Information on anti-smoking advertising expenditures was obtained from officials in 


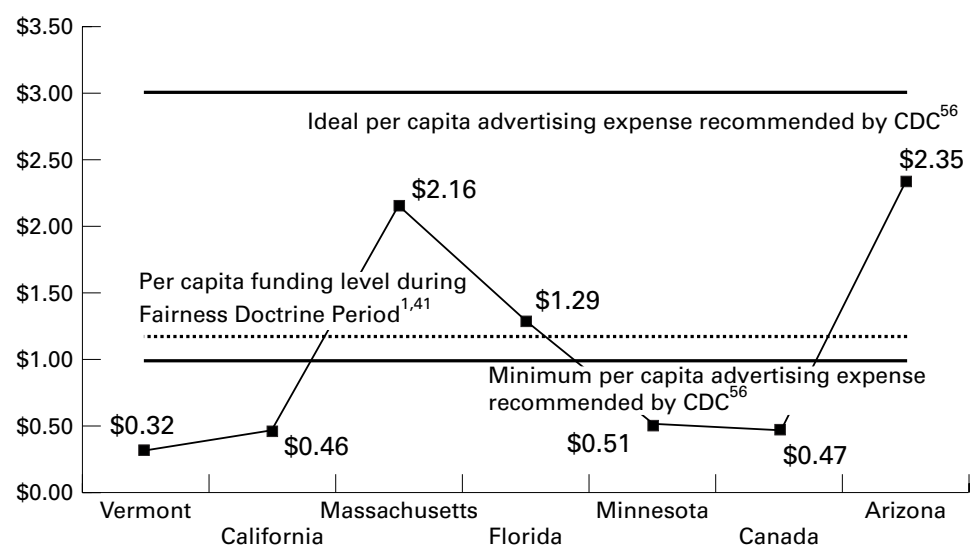

Figure 1 Comparison of adjusted per capita anti-smoking advertising expenses, 1985 to present. For California, Massachusetts, Florida, Canada, per capita expenditures were calculated from average annual budget allocated from campaign inception to 1999 and 1996 population estimates. ${ }^{46-51}$ Per capita cost for Minnesota reflects the average annual budget from the entire campaign (1986 to 1990) and 1996 population estimates, adjusted to 1996 dollars. ${ }^{4{ }^{52} 53}$ Costs for Vermont were calculated from published estimates for replicating the campaign at national level (in 1996 dollars) and 1996 national population estimate. ${ }^{97}$ Funding level during Fairness Doctrine was calculated from estimated expenditures of \$298 million (in 1996 dollars) divided by 1996 US population estimates. ${ }^{41} 4754$

each US state (Arizona, California, Florida, Massachusetts, Minnesota), Canada (Health Canada), and Vermont. We also consulted published sources and the internet. For each campaign, an average expenditure across all available years was computed and then converted to per capita amounts by dividing by the 1996 USA census population estimate for the relevant geographic area. The per capita amount provides a control for differences in population sizes. For instance, since California is a more populated state, it needs a larger advertising budget to reach everyone who is to be targeted.

For California ${ }^{46}{ }^{47}$ (telephone conversation with Curt Fallor, California Tobacco Control Section, December 1999), Massachusetts ${ }^{47} 48$ (email correspondence with Mark LaPlante, Massachusetts Department of Health Services, February 2000), Florida, ${ }^{49}{ }^{49}$ Canada, ${ }^{50}$ and Arizona (telephone conversation with Robert Suiter, Arizona Tobacco Education and Prevention, February 2000) $)^{47}$ the per capita figure reflects the average annual budget from campaign inception to 1999 . The per capita cost for Minnesota reflects the average annual budget for the complete campaign that occurred from 1986 to 1990 . This figure was then adjusted to 1996 dollars using the consumer price index. ${ }^{47-54}$ The Vermont campaign was conducted in communities across several states in the USA between 1985 and 1989. The researchers estimated that it would cost $\$ 84.5$ million, in 1996 dollars, to replicate nationally. We divided this amount by the 1996 USA population to obtain a per capita estimate. ${ }^{475}$

Figure 1 shows, for each campaign, the estimated per capita cost for all anti-smoking advertising, across all audiences. Information about the money spent strictly on youth was generally not available and thus not reported. We do not report how campaign expenditures changed over the years, because of incomplete data, but this issue is discussed in relevant places in the text. Figure 1 further illustrates the minimum and optimal per capita funding levels recommended by the Centers for Disease Control and Prevention (CDC) (in 1999 dollars), ${ }^{56}$ and the estimated value of the anti-smoking advertisements run during the Fairness Doctrine Era $(\$ 1.12$ in 1996 dollars). ${ }^{1}{ }^{4}$ As a basis for comparison, tobacco firms currently spend over $\$ 7$ per capita per year in the USA on advertising, promotional items, and sponsorships. ${ }^{53}$

ANALYSES OF CAMPAIGN EFFECTIVENESS Reports on the Minnesota and Vermont campaigns have appeared in academic journals, so we relied on those publications to assess the effects. ${ }^{7852}$ Both campaigns were evaluated by tracking weekly smoking prevalences over time in intervention and control communities using school based surveys. In Canada, current (last 30 day) adolescent smoking prevalences have been tracked since 1970 using personal and confidential home surveys. The data, and trends over time, have been reported in an academic article so we relied on that article. ${ }^{50}$

To evaluate the remaining campaigns, we used data from the sponsoring state and an appropriate comparison area (see below) to provide a baseline or control group. ${ }^{57}$ Since multiple data sources were available, we used the following selection criteria to minimise potential bias. First, we relied on academic journals or official government or university reports. Second, we used sources with two or more years of data so that we could assess changes in smoking prevalence. Third, the intervention and control (baseline) data pertained to youth in the same grade in school, collected in the same year, using the same measure: 30 day prevalence or current smoking (that is, any smoking within the past 30 days). Finally, we used surveys completed by random pools of subjects from randomly selected schools. We relied on school based surveys because, in phone surveys, youth generally report substantially less smoking behaviour. ${ }^{58}$ It seems that youths are hesitant to respond honestly about illicit tobacco use over the phone because they fear being overheard by family members. ${ }^{58} 59$

Following these criteria, in virtually all cases, we relied on data collected by the states in cooperation with the CDC and its Youth Risk Behavior Survey (YRBS). The single exception was California where state specific data from Monitoring the Future were available and where the state's own surveys were phone based. Monitoring the Future also provided regional comparison data for Massachusetts and Florida, and US comparison data for California. California uses national (versus regional) data as its benchmark since the state represents roughly $69 \%$ of the western region, according to the US census. ${ }^{47}$ For Arizona, there was only one state specific data point available, stemming from a phone survey conducted more than two years after the campaign had commenced. ${ }^{51}$ Hence, we do not report on the effects of Arizona's campaign. 
Table 1 Trends in youth smoking prevalence: Vermont campaign, 1985 to 1989

\begin{tabular}{lllllll}
\hline \multicolumn{7}{l}{ Reported weekly smoking prevalence } \\
\cline { 2 - 7 } & $\begin{array}{l}\text { Grade 6 } \\
1985\end{array}$ & $\begin{array}{l}\text { Grade } 7 \\
1986\end{array}$ & $\begin{array}{l}\text { Grade } 8 \\
1987\end{array}$ & $\begin{array}{l}\text { Grade } 9 \\
1988\end{array}$ & $\begin{array}{l}\text { Grade } 10 \\
1989\end{array}$ & $\begin{array}{l}\text { Grade 12: 2 years } \\
\text { postintervention 1991 }\end{array}$ \\
\hline Intervention & 1.3 & 1.8 & $5.0^{\star}$ & $9.1^{\star}$ & $12.8^{\star}$ & $16^{\star}$ \\
Control & 1.6 & 3.4 & 9.3 & 14.8 & 19.8 & 24 \\
\hline
\end{tabular}

Source: Flynn et al.

${ }^{\star} \mathrm{p} \leqslant 0.05$

STATISTICAL ANALYSES

Tables 1 to 6 indicate the changes in adolescent smoking prevalence in the campaign and control (baseline) areas across relevant comparison years. Results for the Vermont study, Minnesota, and Canada are summarised as published. ${ }^{80}{ }^{52}$ Vermont researchers used a stepwise regression procedure to assess treatment effects between the intervention and control groups. ${ }^{78}$ Minnesota evaluators analysed that state's results using a hierarchical ANCOVA that compared the mean square effect for the state by year interaction against the mean square effect for school within state by year. ${ }^{52}$ This approach, while appropriate, was conservative and could possibly have underestimated the effects for Minnesota. The Canadian data were fit to stochastic models that estimated coefficients for trends, changes in trends, and random fluctuations in prevalences, by sex. ${ }^{50}$ If the Canadian advertising campaign had lowered adolescent smoking prevalence, a significant change in trend would have been observed.

For California, Massachusetts, Florida, and each selected comparison area, we calculated relative risk ratios using the PROC FREQ function in SAS. The ratios reflect between year comparisons of the proportions of adolescents who reported smoking within the past 30 days, with the uncertainty in each estimate being expressed by the $95 \%$ confidence interval (CI). The higher the ratio, the higher the smoking prevalence (risk). A confidence interval that does not contain 1.00 indicates a significant change (increase or decrease) in the risk of smoking over time. ${ }^{60}$

For example, the relative risk from 1997 to 1999 among Massachusetts 10th graders was 0.82 . This value is significant because the $95 \%$ CI of 0.72 to 0.92 does not contain 1.00. The value also indicates that the overall risk for 30 day smoking prevalence was significantly lower in 1999 than in 1997. Absolute changes in prevalence are also reported in tables 1 to 6 and significant effects are flagged. Tests of absolute changes were conducted using the $\mathrm{z}$ statistic, but the results are identical to those using relative risk. All comparisons controlled for grade in school and geographic area-for example, Massachusetts 10th graders in 1997 were compared to that state's 10th graders in 1999, and so forth. Table 7 contains the estimated sample sizes used for the calculations in tables 1 to 6 . For details on the sample sizes, see notes at the foot of table 7 .

We concluded that an advertising campaign lowered adolescent smoking prevalence from time $t$ to $t+n$ (for example, 1997 to 1999) if (a) the focal area showed a significant decrease in prevalence and there was either no significant change or a significant increase in the comparison area, or (b) the prevalence was flat in the focal area and increased significantly in the comparison area. If there was no significant difference between the focal and comparison areas (that is, if both experienced increases in, decreases in, or constant prevalences), we concluded that the campaign had no effect during that period for that grade. In a few cases smoking prevalence significantly increased in the intervention (versus comparison) area. Factors extraneous to the campaign (for example, societal norms) or conceivably the campaign itself could have contributed to the increase. Since we could not distinguish between these competing explanations, we do not interpret these results.

Figure 2 provides data about each sponsor on each advertising message variable-namely, content, efficacious content, clarity, and consistency. For each sponsor, we used SPSS to compute crosstabs and $\chi^{2}$ tests comparing the frequency (prevalence) of use of different message content. The results of these within sponsor analyses are included in fig 2. The messages shown by black bars were used by the sponsor significantly more than the messages designated by white bars $(\mathrm{p}<0.05)$. The messages depicted by grey bars were not used sig-

Table 2 Trends in youth smoking prevalence: California campaign, 1990 to present

\begin{tabular}{|c|c|c|c|c|c|c|c|c|c|c|}
\hline & \multirow[b]{2}{*}{ Grades } & \multicolumn{2}{|c|}{$\begin{array}{l}\text { Reported } 30 \text { day } \\
\text { smoking prevalence }\end{array}$} & \multicolumn{3}{|c|}{ Change in smoking prevalence 1993 to 1995} & \multirow{2}{*}{$\begin{array}{l}\text { Reported } 30 \\
\text { day smoking } \\
\text { prevalence } 1997\end{array}$} & \multicolumn{3}{|c|}{ Change in smoking prevalence 1995 to 1997} \\
\hline & & 1993 & 1995 & $\begin{array}{l}\text { Change } \\
\text { in } \%\end{array}$ & $\begin{array}{l}\text { Relative } \\
\text { risk }\end{array}$ & $\begin{array}{l}95 \% \text { CI for } \\
\text { relative risk }\end{array}$ & & $\begin{array}{l}\text { Change } \\
\text { in \% }\end{array}$ & $\begin{array}{l}\text { Relative } \\
\text { risk }\end{array}$ & $95 \% C I$ \\
\hline California & 8th & 12.0 & 12.0 & 0 & 1.00 & 0.74 to 1.35 & 14.0 & +2.0 & 1.17 & 0.83 to 1.54 \\
\hline & 8th & 16.7 & 19.1 & $+2.4^{\star}$ & $1.14^{\star}$ & 1.05 to 1.25 & 19.4 & +0.3 & 1.02 & 0.94 to 1.10 \\
\hline California & 10th & 18.0 & 18.0 & 0 & 1.00 & 0.78 to 1.29 & 19.0 & +1.0 & 1.06 & 0.82 to 1.36 \\
\hline & 10th & 24.7 & 27.9 & $+3.2^{\star}$ & $1.13^{\star}$ & 1.05 to 1.21 & 29.8 & +1.9 & 1.07 & 0.99 to 1.14 \\
\hline
\end{tabular}

Source: Monitoring the Future California - specific data published in final report: independent evaluation of the California tobacco control prevent and education program: wave 1 data, 1996 to 1997 . Monitoring the Future data also used for national (USA) comparisons. ${ }^{65,66}$ program: 


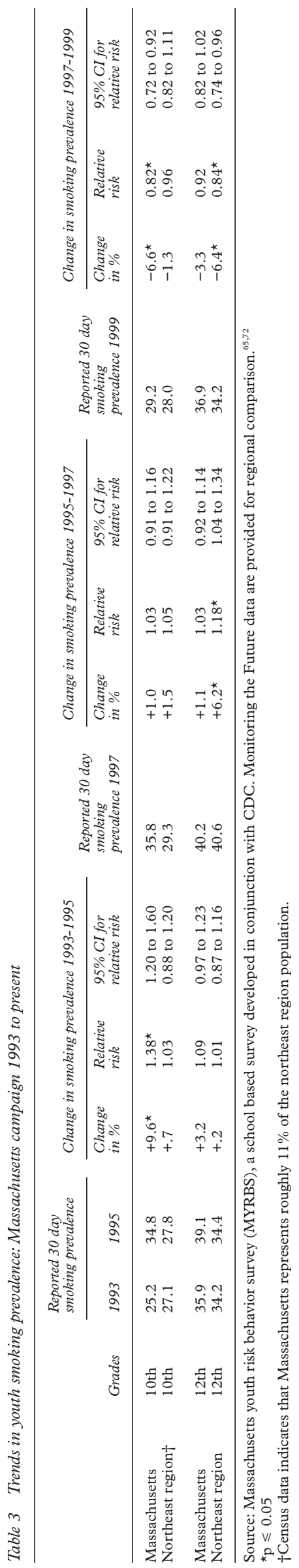

nificantly more or less than any other messages.

Figure 3 contains data about each sponsor on each advertising execution variable, namely, use of youthful spokespeople and depictions of smoking. We used SPSS crosstabs and $\chi^{2}$ tests to make the between sponsor comparisons shown. A black (versus white) bar indicates significantly greater use of the designated executional device by one sponsor versus another $(\mathrm{p}<0.05)$. Grey bars indicate no significant differences.

\section{Detailed results for each advertising campaign}

COST EFFECTIVENESS RANKINGS

Table 8 ranks the advertising campaigns from best to worst in terms of their cost effectiveness at dissuading youth from smoking. The findings indicate that one campaign was highly cost effective, three achieved modest effects at varying funding levels, two did not work, and the results for Arizona are unknown. Vermont's campaign worked very well by achieving significant effects inexpensively (\$0.32 per capita) ${ }^{55}$ California is ranked after Vermont on cost effectiveness because its campaign resulted in modest effects at a low per capita cost $\left(\$ 0.46^{46}\right.$; telephone conversation with Curt Fallor, California Tobacco Control Section, December 1999). Massachusetts and Florida rank next because they attained modest effects while spending substantially more per capita $\left(\$ 2.16^{48}\right.$; email correspondence with Mark LaPlante, Massachusetts Department of Health Services, February 2000 and $\$ 1.29^{49}$ respectively). Minnesota's campaign was inexpensive $(\$ 0.51 \text { per capita })^{53}$ but did not achieve any significant effects. Canada's campaign, with a per capita budget of $\$ 0.47,{ }^{50}$ was not successful either. Arizona spent $\$ 2.35$ per capita but a lack of behavioural outcome data prevents an analysis of cost effectiveness (telephone conversation with Robert Suiter, Arizona Department of Tobacco Education and Prevention, February $2000)^{51}$ (see both fig 1 and table 8 ).

PREDICTORS OF COST EFFECTIVENESS

Table 8 further ranks the campaigns on each advertising variable that was measured due to its potential association with cost effectiveness (in terms of lowering adolescent smoking prevalence). All but one of the variables does seem to be associated with cost effectiveness. The more cost effective campaigns generally utilised a larger percentage of messages that, based on prior research, seem to be especially efficacious at dissuading youth from smoking. Typically, the more cost effective campaigns showed greater consistency in terms of emphasising a single efficacious message. Campaigns that ranked higher on cost effectiveness generally avoided unclear messages and employed youthful spokespeople more often. The frequency of depictions of smoking behaviour did not seem to be associated with cost effectiveness, however (table 8). 
Table 4 Trends in youth smoking prevalence: Florida campaign 1998 to present

\begin{tabular}{|c|c|c|c|c|c|c|}
\hline & \multirow[b]{2}{*}{ Grades } & \multicolumn{2}{|c|}{$\begin{array}{l}\text { Reported } 30 \text { day } \\
\text { smoking prevalence }\end{array}$} & \multicolumn{3}{|c|}{$\begin{array}{l}\text { Change in smoking prevalence } \\
\text { 1998-1999 }\end{array}$} \\
\hline & & 1998 & 1999 & $\begin{array}{l}\text { Change } \\
\text { in } \%\end{array}$ & $\begin{array}{l}\text { Relative } \\
\text { risk }\end{array}$ & $\begin{array}{l}95 \% \text { CI for } \\
\text { relative risk }\end{array}$ \\
\hline Florida & 8 th & 25.0 & 19.5 & $-5.5^{\star}$ & $0.78^{\star}$ & 0.72 to 0.85 \\
\hline South region $\dagger$ & 8 th & 21.1 & 18.7 & -2.4 & 0.87 & 0.77 to 1.02 \\
\hline Florida & 10th & 25.5 & 24.4 & -1.1 & 0.96 & 0.86 to 1.07 \\
\hline South region & 10th & 29.8 & 26.3 & $-3.5^{\star}$ & $0.88^{\star}$ & 0.78 to 0.99 \\
\hline Florida & 12 th & 29.8 & 27.8 & -2.0 & 0.93 & 0.85 to 1.03 \\
\hline South region & 12th & 34.3 & 36.2 & +1.9 & 1.06 & 0.95 to 1.17 \\
\hline
\end{tabular}

Source: Florida Youth Tobacco Survey (FYTS), a school based survey developed in conjunction with CDC.

Monitoring the Future data are provided for regional comparison. ${ }^{65,75}$

$\star_{\mathrm{p}} \leqslant 0.05$

tCensus data indicates that Florida represents roughly $16 \%$ of the south region population.

Table 5 Trends in youth smoking prevalence: Minnesota campaign 1986 to 1990

\begin{tabular}{lllll}
\hline & Grades & 1986 & 1990 & $\begin{array}{l}\text { Change in \% } \\
\text { from 1986-1990 }\end{array}$ \\
\hline Intervention (Minnesota) & 9th & 12.6 & 10.3 & -2.3 \\
Control (Wisconsin) & 9 th & 15.8 & 15.9 & +0.1 \\
Intervention versus control & 9 th & -3.2 & -5.6 & -2.4 \\
\hline
\end{tabular}

Source: Murray et al. ${ }^{52}$

\section{Vermont}

COST EFFECTIVENESS

The campaign that was undertaken by Vermont researchers sought to stress the positive consequences of non-smoking, model refusal skills, convey the immediate social and physical problems associated with smoking, and teach adolescents about cigarette marketing. ${ }^{761}$ It ranks as the most cost effective because it achieved significant reductions in smoking prevalence with a low per capita budget. ${ }^{61}$ The campaign ran from 1985 to 1989 as a part of a multi-community experimental trial. $^{55}$

The two intervention communities received mass media advertisements and a school program; the two control communities received only the school program. At the onset, the students were in grades 6 and their weekly smoking prevalence was less than $2 \%$. By the time they had reached grade 8 , the intervention group was smoking significantly less than the control group (intervention 5.0\%, control $9.3 \% ; \mathrm{p}<0.05)$. Two years later, smoking prevalence in the intervention group remained significantly lower (intervention $12.8 \%$, control $19.8 \% ; \mathrm{p}<0.05) .{ }^{81}$ The effects were sustained for at least two years after the campaign ceased (intervention 16\%, control $24 \% ; \mathrm{p}<0.05){ }^{8}$

PREDICTORS OF COST EFFECTIVENESS

It appears that the success of the Vermont campaign can be attributed to a variety of factors. Based on our results, $79 \%$ of the advertisements communicated message content that prior research found to be efficacious with youth. Advertisements with the refusal skills theme comprised $58 \%$ of the campaign which indicates a very high degree of consistency over time. Two other efficacious themes were used: deceptive portrayal of lethal product $(13 \%)$ and smoker as negative role model $(8 \%)$. Only $4 \%$ of Vermont's messages were deemed unclassifiable (meaning low agreement on message).

Executional factors may have also contributed to Vermont's success. In particular, $70 \%$

Table 6 Trends in youth smoking prevalence: Canada 1985 to present

\begin{tabular}{|c|c|c|c|c|c|c|c|c|c|c|c|c|c|c|c|}
\hline & \multicolumn{14}{|c|}{ Reported 30 day smoking prevalence } & \multirow{2}{*}{$\begin{array}{l}\text { Trend and change in } \\
\text { trend 1970-1995 }\end{array}$} \\
\hline & 1970 & 1974 & 1975 & 1977 & 1979 & 1981 & 1983 & 1985 & 1986 & 1989 & 1990 & 1991 & 1994 & 1995 & \\
\hline Males $15-19$ years & 39.0 & 38.0 & 35.0 & 32.0 & 31.0 & 27.0 & 25.0 & 27.0 & 23.5 & 21.6 & 21.5 & 19.7 & 27.0 & 24.6 & $\begin{array}{l}\text { Trend: } 0.8^{\star} \\
\text { Change in trend: NS }\end{array}$ \\
\hline Females $15-19$ years & 29.0 & 33.0 & 33.0 & 32.0 & 31.0 & 28.0 & 24.0 & 28.5 & 27.0 & 23.5 & 21.4 & 25.6 & 29.5 & 25.2 & $\begin{array}{l}\text { Trend: }-0.1^{\star} \\
\text { Change in trend: NS }\end{array}$ \\
\hline
\end{tabular}

Source: Pechmann and Dixon. ${ }^{50}$

$\star$ Significance $\mathrm{p}<0.05$

NS, not significant.

Table 7 Approximate sample sizes for youth smoking prevalence results

\begin{tabular}{|c|c|c|c|c|c|c|c|c|c|c|c|c|c|c|}
\hline Location & Data source & Grade & 1985 & 1986 & 1987 & 1988 & 1989 & 1990 & 1991 & 1993 & 1995 & 1997 & 1998 & 1999 \\
\hline Vermont & Flynn $e t a l^{78}$ & $6-12$ & 5458 & 5458 & 5458 & 5458 & 5458 & & 4670 & & & & & \\
\hline \multirow[t]{2}{*}{ California } & Monitoring the Future ${ }^{66}$ & 8 & & & & & & & & 600 & 636 & 708 & & \\
\hline & Monitoring the Future ${ }^{66}$ & 10 & & & & & & & & 490 & 581 & 508 & & \\
\hline Massachusetts & MYRBS $^{72}$ & 10 or 12 & & & & & & & & 830 & 1040 & 996 & & 1104 \\
\hline \multirow{2}{*}{ Northeast region } & Monitoring the Future ${ }^{65}$ & 10 & & & & & & & & 763 & 868 & 868 & & 789 \\
\hline & Monitoring the Future ${ }^{65}$ & 12 & & & & & & & & 711 & 737 & 868 & & 658 \\
\hline \multirow[t]{2}{*}{ Florida } & FYTS $^{75}$ & 8 & & & & & & & & & & & 3836 & 3634 \\
\hline & FYTS $^{75}$ & 10 or 12 & & & & & & & & & & & 2029 & 1828 \\
\hline \multirow[t]{3}{*}{ South region } & Monitoring the Future ${ }^{65}$ & 8 & & & & & & & & & & & 1737 & 1605 \\
\hline & Monitoring the Future ${ }^{65}$ & 10 & & & & & & & & & & & 1368 & 1237 \\
\hline & Monitoring the Future ${ }^{65}$ & 12 & & & & & & & & & & & 1500 & 1289 \\
\hline Minnesota & Murray et $a \bar{l}^{2}$ & 9 & & 3580 & & & & 3926 & & & & & & \\
\hline Wisconsin & Murray et $a \bar{F}^{2}$ & 9 & & 3576 & & & & 3190 & & & & & & \\
\hline Canada & $\begin{array}{l}\text { Health Canada, in } \\
\text { Pechmann et a } P^{0}\end{array}$ & $\begin{array}{l}15-19 \text { year } \\
\text { olds }\end{array}$ & 3038 & 3038 & & & 3038 & 3038 & 3038 & & 3038 & & & \\
\hline \multirow[t]{2}{*}{ USA } & Monitoring the Future ${ }^{65}$ & 8 & & & & & & & & 4816 & 4605 & 4895 & & \\
\hline & Monitoring the Future ${ }^{65}$ & 10 & & & & & & & & 4026 & 4474 & 4079 & & \\
\hline
\end{tabular}

Monitoring the Future sample sizes reflect the reported weighted n's divided by a 3.8 design effect. We did this to align our analyses with standard Monitoring the Future analyses (telephone conversation with Tim Perry, Monitoring the Future, February 2000).

The sample sizes associated with the California specific Monitoring the Future results were not available and so we estimated them. Specifically, we calculated the sample size for each grade as $69 \%$ of the reported western region sample.

The MYRBS and FYTS grade specific sample sizes were not available and so we estimated them. Specifically, we calculated them as percentages of the reported middle and high school samples as follows: grade $8=33 \%$ of middle school sample, grade $10=25 \%$ of high school sample, grade $12=25 \%$ of high school sample 


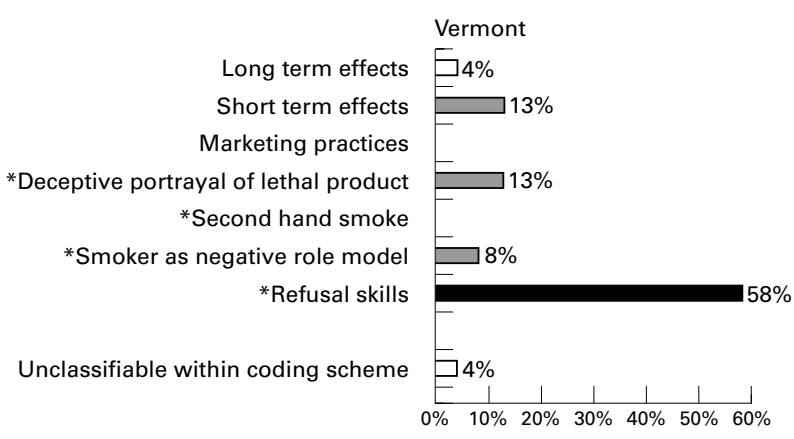

*Estimated percentage of ads using most efficacious message content $=79 \%$

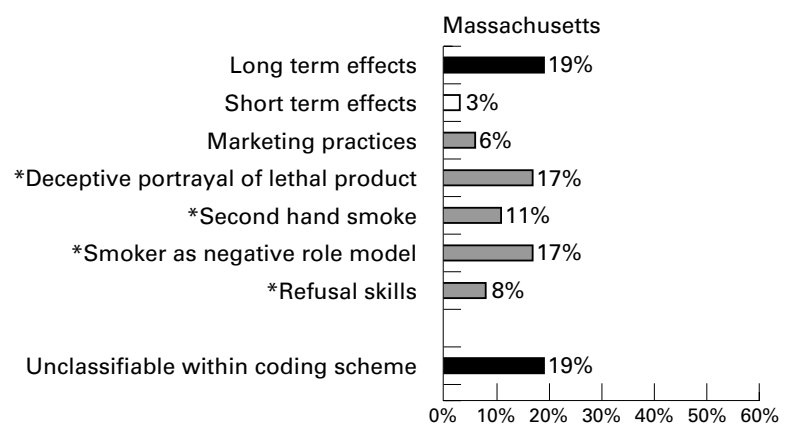

*Estimated percentage of ads using most efficacious message content $=53 \%$

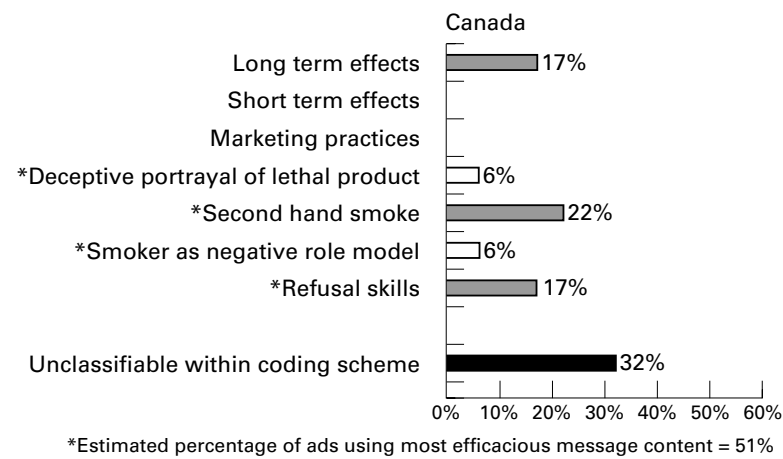

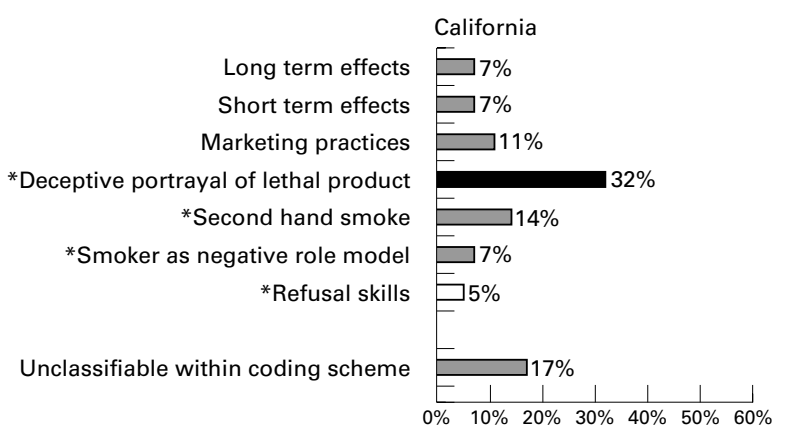

*Estimated percentage of ads using most efficacious message content $=58 \%$

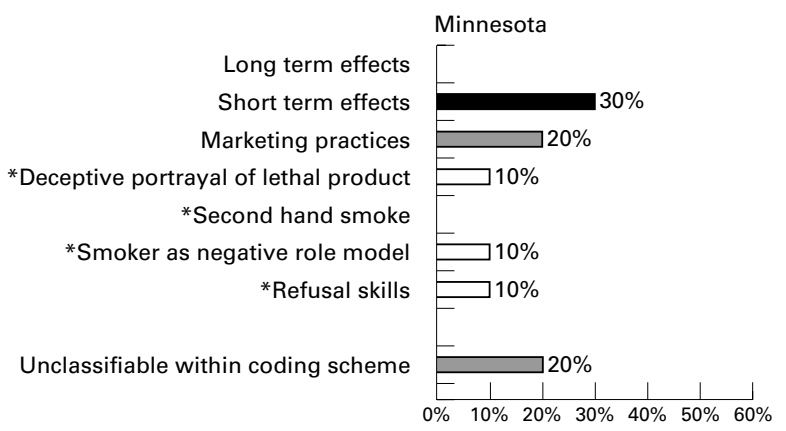

*Estimated percentage of ads using most efficacious message content $=30 \%$

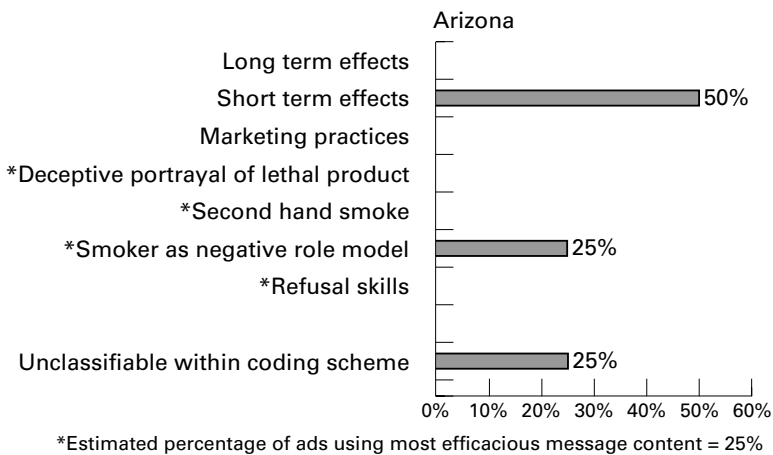

Figure 2 Messages used in advertisements as identified by middle school and high school students (within campaign comparisons). Solid black and white bars within each figure differ significantly $(p<0.05)$. Grey bars do not differ significantly from each other or from black and white bars.

of Vermont's advertisements featured youthful spokespeople which may have enhanced the campaign's relevance to its target audience. While $46 \%$ of the advertisements depicted smoking, apparently the depictions were unflattering and reinforced the anti-smoking messages. Overall, the Vermont researchers mounted a homogeneous and effective campaign that can serve as a model for states considering anti-smoking advertising.

\section{California}

COST EFFECTIVENESS

California chose to emphasise the health effects of second hand smoke and to attack the tobacco industry for selling a lethal and addictive product and targeting kids. ${ }^{62}$ The campaign, started in 1990 after voters approved a tobacco excise tax hike, has had moderate success. ${ }^{19}{ }^{64}$ Since the campaign was relatively inexpensive, it ranks second in terms of cost effectiveness.

Our findings indicate that from 1993 to 1995 the California campaign realised some positive results. Although smoking prevalences among California eighth and 10th graders remained flat during this time, nationally there were significant increases in smoking prevalences in both grades (for eighth graders: California relative risk $1.00,95 \%$ CI 0.74 to 1.35; US relative risk $1.14,95 \%$ CI 1.05 to 1.25; for 10th graders: California relative risk $1.00,95 \%$ CI 0.78 to 1.29 ; US relative risk $1.13,95 \%$ CI 1.05 to 1.21$)$. From 1995 to 1997, there is little indication that California's campaign was impacting youth. For grades 8 and 10 , while smoking prevalences continued to be flat in California, nationally the prevalences were flat as well. ${ }^{65}{ }^{66}$ One reason may be that the California advertising budget was cut; it has also been speculated that the California advertisements became less hard hitting. ${ }^{46} 67$

PREDICTORS OF COST EFFECTIVENESS

There are several reasons why California seems to have had some success. First, $58 \%$ of its advertisements used message themes that prior research identified as being efficacious with adolescents. One such theme-deceptive 
A Main character appears to be under 25 years old

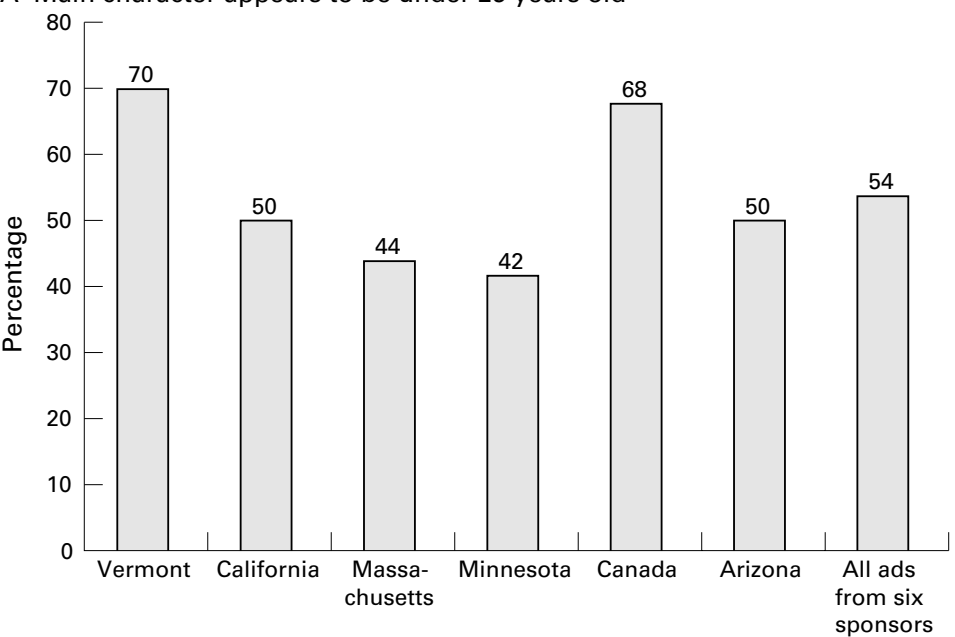

B People shown smoking cigarettes

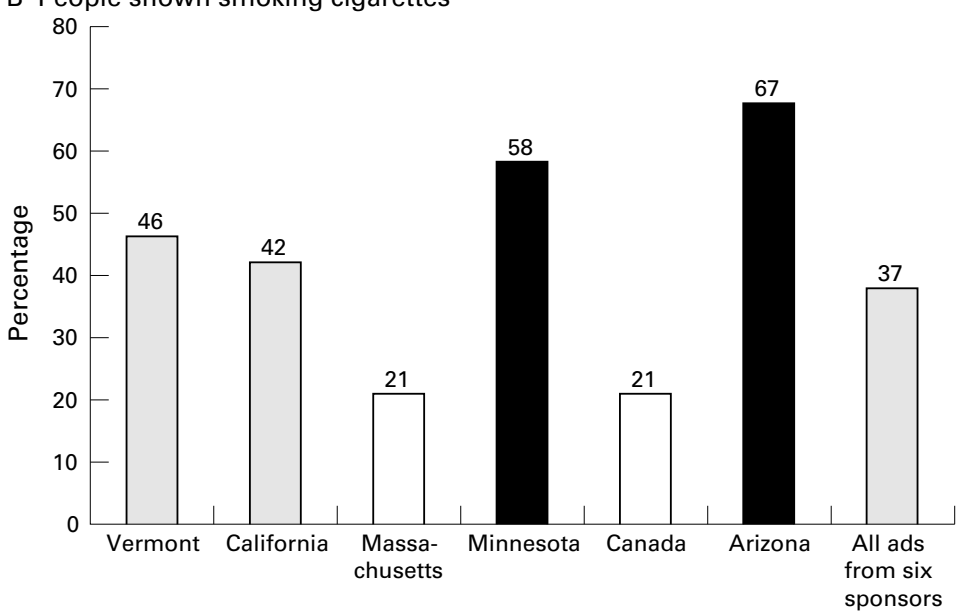

Figure 3 Use of youthful spokespeople and depiction of people smoking (across campaign comparisons). Solid black and white bars within each figure differ significantly $(p<0.05)$. Grey bars do not differ significantly from each other or from black and white bars.

portrayal of lethal product-was used in 32\% of the advertisements. This indicates a relatively high degree of consistency over time. California used additional efficacious themes: second hand smoke (14\%), smoker as negative role model $(7 \%)$, and refusal skills $(5 \%)$. Only $17 \%$ of California's advertisements were rated as unclassifiable, meaning that the majority were readily comprehended. Executionally, $50 \%$ of the California advertisements featured youthful spokespeople which was about average across the sponsors. Smoking behaviour was modelled in $42 \%$ of the California advertisements which was also about average.

\section{Massachusetts}

COST EFFECTIVENESS

Convincing 9 to 17 year olds not to smoke is one of three major objectives of the Massachusetts campaign. ${ }^{68} \mathrm{~A}$ primary message is to communicate the "harsh medical realities of the effects of smoking". ${ }^{62}{ }^{69}$ Additional messages include second hand smoke, cosmetic effects, and testimonials from ex-employees and former supporters of the tobacco industry. ${ }^{62} 70$ The surtax funded campaign started in 1993 and has had modest success. ${ }^{71}$ Similar to California, there is evidence that adolescent smoking prevalence decreased in some instances, but the per capita spending to achieve this result was higher. As such, we rank Massachusetts third (tied with Florida) on cost effectiveness.

From 1993 to 1995, there is little indication that the Massachusetts campaign dissuaded many high school students from smoking. In fact, smoking prevalence among Massachusetts 10 th graders increased significantly while rates in the northeast region remained flat (Massachusetts relative risk 1.38, 95\% CI 1.20 to 1.60 ; northeast relative risk $1.03,95 \% \mathrm{CI}$ 0.88 to 1.20$).{ }^{65}{ }^{72}$ For 12 th graders, the smoking prevalence in both Massachusetts and the region remained flat. ${ }^{6572}$

Since 1995, the Massachusetts campaign yielded mixed results. From 1995 to 1997, smoking prevalence among Massachusetts 12th graders was stable while prevalence increased regionally (Massachusetts relative risk $1.03,95 \%$ CI 0.92 to 1.14 ; northeast relative risk $1.18,95 \%$ CI 1.04 to 1.34$).{ }^{65}{ }^{72}$ From 1997 to 1999, smoking prevalence among Massachusetts 10th graders decreased significantly while the regional prevalence remained flat (Massachusetts relative risk $0.82,95 \%$ CI 0.72 to 0.92 ; northeast relative risk $0.96,95 \%$ CI 0.82 to 1.11 ). On the other hand, from 1995 to 1997, prevalence for 10th graders in both Massachusetts and the region remained flat. From 1997 to 1999, the Massachusetts 12 th grade prevalence remained flat while the region experienced a significant decrease (Massachusetts relative risk $0.92,95 \%$ CI 0.82 to 1.02 ; northeast relative risk $0.84,95 \% \mathrm{CI}$ 0.74 to 0.96$).{ }^{65} 72$

Table 8 Summary of case study findings: advertising cost effectiveness and possible predictors

\begin{tabular}{|c|c|c|c|c|c|c|}
\hline \multicolumn{2}{|l|}{ Cost effectiveness } & \multicolumn{5}{|c|}{ Possible predictors of cost effectiveness } \\
\hline Advertising sponsor & Ranking ${ }^{\star}$ & $\begin{array}{l}\% \text { ads with efficacious } \\
\text { messages: total across all } \\
\text { messages }\end{array}$ & $\begin{array}{l}\% \text { ads with efficacious } \\
\text { message: highest incidence } \\
\text { message }\end{array}$ & $\begin{array}{l}\% \text { unclassifiable ads } \\
\text { (<80\% agreement on } \\
\text { message) }\end{array}$ & $\begin{array}{l}\% \text { ads using youthful } \\
\text { spokespeople }(<25 \\
\text { years old })\end{array}$ & $\begin{array}{l}\% \text { ads depicting } \\
\text { smoking behaviour }\end{array}$ \\
\hline Vermont & 1 & 79 & 58 & 4 & 70 & 46 \\
\hline California & 2 & 58 & 32 & 17 & 50 & 42 \\
\hline Massachusetts & 3 & 53 & 17 & 19 & 44 & 21 \\
\hline Florida & 3 & N/A & N/A & N/A & N/A & N/A \\
\hline Minnesota & 4 & 30 & 10 & 20 & 42 & 58 \\
\hline Canada & 5 & 51 & 22 & 32 & 68 & 21 \\
\hline Arizona & Unknown & 25 & 25 & 25 & 50 & 67 \\
\hline
\end{tabular}

${ }^{\star}$ Ranking: $1=$ most cost effective, $5=$ least cost effective.

N/A/, not applicable. 
PREDICTORS OF COST EFFECTIVENESS

The moderate success experienced in Massachusetts may be owed to the fact that $53 \%$ of the advertisements appeared to contain efficacious content for youth, including: deceptive portrayal of lethal product $(17 \%)$, smoker as negative role model $(17 \%)$, second hand smoke (11\%), and refusal skills (8\%). Just 19\% of the Massachusetts advertisements were found to be unclassifiable; the majority contained clearcut messages. However, the campaign distributed advertisements across several themes instead of concentrating on a few themes with a consistency rating of only $17 \%$. While youths were prominently featured in $44 \%$ of the Massachusetts advertisements, other sponsors utilised youths more. Finally, the Massachusetts advertisements were significantly less likely to depict people smoking than some of the other sponsors.

\section{Florida}

COST EFFECTIVENESS

Florida seeks to incite youths to activism against the tobacco industry to punish it for deception and immorality. The campaign tagline is "Their brand is lies. Our brand is truth". ${ }^{73}$ Florida youth are involved in campaign planning and are encouraged to form SWAT (Students Working Against Tobacco) clubs to support its goals. ${ }^{74}$ The highly visible campaign commenced in 1998. It has had modest success in its first year, in that there is evidence that smoking prevalence decreased in one grade level. Hence, we rank Florida as tied with Massachusetts in terms of cost effectiveness.

Specifically, Florida's campaign has had some apparent success with eighth graders. Between 1998 and 1999, smoking prevalence among Florida eighth graders dropped significantly while regional rates remained flat (Florida relative risk $0.78,95 \%$ CI 0.72 to 0.85 ; south relative risk $0.87,95 \%$ CI 0.77 to 1.02) ${ }^{65}{ }^{75}$ However, prevalence among Florida 10 th graders remained flat in comparison to a significant regional decline (Florida relative risk $0.96,95 \%$ CI 0.86 to 1.07 ; south region relative risk $0.88,95 \%$ CI 0.78 to 0.99$).^{6575}$ The trend for Florida 12th graders mirrored the flat regional trend.

PREDICTORS OF COST EFFECTIVENESS

Our analysis of the Florida campaign is limited because we lack quantitative data on the advertising messages and executions. It appears, however, that Florida may be employing a novel theme that focuses on youth activism. Additional research should be conducted on this theme and its effectiveness with both younger and older youth audiences. The Florida campaign is consistently referred to in the popular press by its "Truth" tagline, ${ }^{49} 62$ which seems to indicate that a consistent message is being conveyed. Also according to reports, Florida uses many youthful spokespeople in its advertisements. ${ }^{4962}$ The Florida campaign is only one year old and more research is needed to quantify Florida's use of these strategies and to assess campaign efficacy.

\section{Minnesota}

COST EFFECTIVENESS

Minnesota has the distinction of being the first US state to initiate an anti-smoking advertising campaign. The campaign started in 1986 but a state budget crisis reportedly led to its demise around $1990 .^{52}$ Minnesota chose to utilise the short-term cosmetics effects theme. Specifically, it decided to focus on the "unpleasant social and personal consequences such as bad breath [and] smelly clothes". Minnesota further stated that it wanted to avoid anti-industry messages. ${ }^{76}$ The Minnesota campaign was reportedly unsuccessful in terms of significantly reducing adolescent smoking prevalence, so we rank it fourth on cost effectiveness.

Minnesota's outcomes were compared to matched communities in Wisconsin where the anti-smoking advertising was not broadcast. ${ }^{52}$ The weekly smoking prevalence among Minnesota ninth graders declined during the campaign $(-2.3 \%) .^{52}$ In the neighbouring state of Wisconsin, where no advertisements were running, the weekly smoking prevalence among ninth graders remained essentially constant $(+0.1 \%)$. Unfortunately, the $2.4 \%$ net decline in Minnesota (versus Wisconsin) was not significant $(p>0.30) .^{52}$

\section{PREDICTORS OF COST EFFECTIVENESS}

There are some apparent factors that may have contributed to Minnesota's lack of success. The theme that was used most often, short term cosmetics effects $(30 \%)$, now does not appear to be particularly efficacious among youth. While $30 \%$ of the advertisements apparently contained more efficacious messages, the campaign's consistency score was just $10 \%$ (deceptive portrayal of lethal product $10 \%$, smoker as negative role model $10 \%$, refusal skills $10 \%$ ). Forty two per cent of the Minnesota advertisements utilised youthful spokespeople, which was slightly lower than some of the other campaigns. Minnesota also portrayed people smoking in $58 \%$ of its advertisements which was significantly higher than some of the other sponsors.

\section{Canada}

COST EFFECTIVENESS

Canada's advertising campaign is designed to promote "the benefits of being smoke free to young Canadians between $11-17$ ". ${ }^{77}$ It also seeks to highlight the negative long term health effects of smoking and the dangers of second hand smoke. ${ }^{77}$ We rank Canada last on cost effectiveness because there is no evidence that the campaign has succeeded in reducing adolescent smoking prevalence.

The Canada data indicate that, from 1970 to 1991, smoking prevalence among adolescent males declined steadily by nearly one full percentage point per year. ${ }^{50}$ There is no evidence that the advertising campaign that began in 1985 succeeded in accentuating this negative trend. Indeed, in 1992, the trend 
reversed itself and smoking prevalence among adolescent males began increasing by nearly one percentage point a year. ${ }^{50}$ Smoking among adolescent females has fluctuated slightly but sporadically (following a "random walk"), with little net change since $1970 .^{50}$

PREDICTORS OF COST EFFECTIVENESS

It is not entirely clear why Canada's campaign has not been more successful with adolescents. We estimate that $51 \%$ of the Canadian advertisements communicated efficacious messages for this group including: second hand smoke $(22 \%)$, refusal skills $(17 \%)$, deceptive portrayal of lethal product $(6 \%)$, and smoker as negative role model (6\%). Sixty eight per cent of the Canadian advertisements featured youthful spokespeople and only $21 \%$ showed people smoking, which was significantly less than some of the other sponsors. However, we detect two possible shortcomings with the campaign. First, Canada used several, disparate messages which it could probably ill afford to do because its per capita expenditures were low. The most commonly used efficacious message (second hand smoke) appeared in just $22 \%$ of the advertisements. Second, the largest message type by a significant margin was unclassifiable (32\%), suggesting that nearly one third of the Canadian advertisements were poorly comprehended.

\section{Arizona}

COST EFFECTIVENESS

We discuss the Arizona campaign last because its cost effectiveness cannot be ascertained. ${ }^{49}$ According to press releases, the Arizona campaign seeks to make smoking look unattractive and disgusting with the tagline "tumor causing, teeth staining, smelly, puking habit". ${ }^{62} 78$ The advertisements commenced in late 1995 and primarily target adolescents.

\section{PREDICTORS OF COST EFFECTIVENESS}

It is unclear whether Arizona's campaign will succeed in reducing adolescent smoking prevalence. Based on our findings, just $25 \%$ of the advertisements used messages that researchers have identified as especially efficacious for youth. Half of the advertisements strictly discussed short term cosmetic effects. Another $25 \%$ of the advertisements were deemed unclassifiable, indicating disagreement or confusion as to the messages conveyed. Executionally, $50 \%$ of the advertisements used youthful spokespeople which is about average across the sponsors. Arizona showed people smoking in $67 \%$ of the advertisements, significantly more than some of the other sponsors.

\section{Research limitations}

A limitation of the study we have presented is that it does not address the impact of anti-smoking advertisement campaigns on adult smoking prevalence or societal attitudes toward smoking. Our data primarily pertain to adolescents' views of anti-smoking advertising, and the effects of the advertisements on adolescents. This is not to say, however, that anti-smoking advertisements should strictly target adolescents. In fact, advertising can play an important role in encouraging adults to be non-smoking role models and to fight for smoke free policies, restricted tobacco access, and similar initiatives. ${ }^{79} 80$

Limiting anti-smoking advertising to youth may imply that while smoking is not acceptable for kids, it is acceptable for adults, making smoking even more appealing to kids who want to emulate adult behaviour. ${ }^{81}$ An industry marketing document advises: "To reach young smokers, present the cigarette as one of the initiations into adult life . . . the basic symbols of growing up." ${ }^{\prime 1}$ The tobacco industry has, in fact, lobbied for limiting anti-smoking advertising to children, presumably in order to maintain adult market share. ${ }^{19}$

Another weakness of our research is that we could not assess the independent contribution of each measured advertising factor to campaign effectiveness. One reason is that the campaigns' ratings on the advertising variables were highly correlated. In particular, Vermont's campaign was strong on several dimensions. Also, we were precluded from running statistical tests linking our advertising variables to specific behavioural outcomes because, with the exception of Vermont, promising outcomes were attained inconsistently. For instance, Massachusetts was successful (versus the region) with 12 th graders during the period from 1995 to 1997 , but could not replicate this effect during 1997 to 1999 . California's results were promising from 1993 to 1995, but not from 1995 to 1997 . It is possible that California's impact on adolescents was undermined in the mid 1990s by budget cuts, ${ }^{46}$ but we were unable to determine specific information about how the adolescent (versus adult) budget was affected by those cuts. Unfortunately, sponsors generally do not report specific budget allocations for youth versus adults. Such information would be very helpful to future researchers.

An additional limitation of our study is that we could not look at early versus later campaign effects because our data were too sparse. Furthermore, in California our analysis starts a few years after campaign inception owing to a lack of suitable comparison data. In Arizona we could not analyse cost effectiveness because only one state specific data point was available. Additionally, we estimated the survey sample sizes in Massachusetts and Florida since grade specific sample sizes were not reported (see table 7 notes). While our results mirror theirs in terms of significant effects, our confidence interval estimates may be slightly different. Finally, several factors that could possibly have impacted campaign effects were not measured. For example, we did not examine print or outdoor advertising, school or community based educational initiatives, tobacco accessibility or prices. ${ }^{2182}$

\section{General recommendations}

When developing anti-smoking advertisements that are intended to lower adolescent smoking prevalence, messages and executions should be geared to adolescents. Experts repeatedly warn 
that advertising that works with adults generally will not work with teens. ${ }^{39}$ Youth advertising is more effective when "this subculture is addressed in a language it understands and appreciates." 38 In advertising, a "one size fits all" approach is widely recognised as unsuitable. ${ }^{16} 2183$ Specifically, when targeting adolescents, officials should consider using spokespeople who are just slightly older than the intended audience. In addition, the following message themes should be examined seriously, since they seem to have the greatest potential for dissuading youths from smoking: second-hand smoke, smoker as negative role model, refusal skills, and deceptive portrayal of a lethal product.

It also seems important to mount a relatively homogeneous or focused campaign. ${ }^{83}$ While it might appear that larger budgets afford the opportunity for many message themes, a laser (focused) versus shotgun (heterogeneous) approach is more consistent with recommendations from advertising experts. ${ }^{21}$ We also recommend that advertisements be tested for comprehension and persuasion before their use. Pretesting advertisements with the target audience should minimise the likelihood of running spots that are poorly understood, viewed as irrelevant or lacking in credibility. Finally, we recommend that outcome studies of advertising effects be conducted, using valid comparison groups and/or pre-post intervention measures. ${ }^{57}$ Outcome studies will make major contributions to our understanding of anti-smoking advertising effects, help officials to be accountable for the money spent, improve campaign cost effectiveness, and ultimately increase the likelihood that funding will be sustained until the problem of adolescent smoking is significantly alleviated.

Funding from the California Tobacco-Related Disease Research Program is gratefully acknowledged. We also thank Charles LaFlamme, Raana Jarrahian, and Maria E Reneteria for their contributions to this project, and Stanton Glantz and the anonymous reviewers for their helpful suggestions.

1 Hamilton JL. The demand for cigarettes: advertising, the health scare, and the cigarette advertising ban. Review of Economics and Statistics 1974;54:401-11.

2 Lewit EM, Coate D, Grossman M. The effects of government regulation on teenage smoking. Fournal of Law and Economics 1981;24:545-69.

3 Schneider L, Klein B, Murphy KM. Governmental regulation of cigarette health information. Fournal of Law and Economics 1981;24:575-611.

4 Schuster CP, Powell CP. Comparison of cigarette and alcohol advertising controversies. fournal of Advertising 1987, 16:26-33.

5 Warner KE. The effects of the anti-smoking campaign on cigarette consumption. Am f Public Health 1977;67:64550.

6 Perry CL, Kelder SH, Murray DM, et al. Communitywide smoking prevention: long-term outcomes of the Minne-
sota heart health program and the class of $1989 . \mathrm{Am} \mathcal{F}$ sota heart health program an
Public Health 1992;82:1210-6.

7 Flynn B, Worden JK, Secker-Walker RH, et al. Prevention of cigarette smoking through mass media intervention and school programs. Am F Public Health 1992;82:827-34.

8 Flynn B, Worden JK, Secker-Walker RH, et al. Mass media and school interventions for cigarette smoking prevention effects 2 years after completion. Am f Public Health 1994 84:1148-50.

9 Pechmann C, Ratneshwar S. The effects of anti-smoking and cigarette advertising on young adolescents' perceptions of peers who smoke. Fournal of Consumer Research 1994;21:236-51.

10 Pechmann C, Shih CF. Smoking scenes in movies and antismoking advertisements before movies: effects on youth. fournal of Marketing 1999;63:1-13.

11 Bauman KE, Brown JD, Bryan ES, et al. Three mass media campaigns to prevent adolescent cigarette smoking. Prev Med 1991;17:510-30.
12 Ellickson PL, Bell RM, McGuigan K, et al. Preventing adolescent drug use: long-term results of a junior high 列

13 Flay BR, Koepke D, Thomson SJ, et al. Six-year follow-up of the first Waterloo school smoking prevention trial. Am $\mathcal{F}$ Public Health 1989;79:1371-6.

14 Murray DM, Pirie P, Luepker RV, et al. Five- and six-year follow-up results from four seventh-grade smoking prevention strategies. F Behav Med 1989;12:207-18.

15 Pechmann C, Goldberg ME. Evaluation of ad strategies for preventing youth tobacco use. Berkeley, California: California Tobacco Related Disease Research Program, 1998. 16 Belch GE, Belch MA. Introduction to advertising and

17 Mazis MB, Ringold DJ, Perry ES, et al. Perceived age and attractiveness of models in cigarette advertisements. attractiveness of models in cigar
fournal of Marketing 1992;56:22-38.

18 Centers for Disease Control. Columbia marketing panel: tobacco counter-marketing strategy recommendations. Atlanta, 1999 .

19 Goldman LK, Glantz SA. Evaluation of antismoking advertising campaigns. FAMA 1998;279:772-7.

20 Hornik R. Public health education and communication as policy instruments for bringing about changes in behavior. In: Goldberg ME, Gishbein M, Middlestadt SE, eds. Social marketing: theoretical and practical perspectives. Mahway, New Jersey: Lawrence Erlbaum Associates, 1997:45-58.

21 Kotler P, Armstrong G. Principles of marketing. Upper Saddle River, New Jersey: Prentice Hall, 1999.

22 Tellis GJ. Advertising and sales promotion strategy. Reading, Massachusetts: Addison Wesley Longman, 1998.

23 Pollay RW. Hacks, flacks, and counter-attacks: cigarette advertising, sponsored research, and controversies. fournal of Social Issues 1997;53:53-75.

24 Fox RJ, Krugman DM, Fletcher JE, et al. Adolescents' attention to beer and cigarette print ads and associated product warnings. Fournal of Advertising 1998;27:57-70.

25 Jacoby J, Hoyer WD. Viewer miscomprehension of televised communication: selected findings. Fournal of Marketing 1982;46:12-26.

26 Jacoby J, Hoyer WD. The miscomprehension of mass-media advertising claims: a re-analysis of benchmark data. Fournal of Advertising Research 1990;June/July:9-16.

27 Pechmann C, Stewart DW. The effects of comparative advertising on attention, memory, and purchase intentions. Fournal of Consumer Research 1990;17:180-91.

28 Pechmann C. Do consumers overgeneralize one-sided comparative price claims and are more stringent regulations
needed? fournal of Marketing Research 1996;33:150-62.

29 Blankenship B, Breen G. State-of-the-art marketing research. Chicago, Illinois: NTC Business Books, 1992.

30 Packard V. Hidden persuaders. New York: Pocket Books, 1981

31 Rogers S. How a publicity blitz created the myth of subliminal advertising. Public Relations Quarterly 1992-1993; 37:12-17

32 Moore T. The case against subliminal manipulation. Psychology and Marketing 1988;5:297-316.

33 McKenna J, Williams K. Crafting effective tobacco counteradvertisements: lessons from a failed campaign directed at teenagers. Public Health Rep 1998;108:85-9.

34 Schudson M. Symbols and smokers: advertising, health messages, and public policy. In: Rabin RL, Sugarman SD, eds. Smoking policy, law, politics and culture. Oxford University Press: 1993:208-42.

35 Pollay RW, Siddarth S, Siegel M, et al. The last straw? Cigarette advertising and realized market shares among youth rette advertising and realized market shares an

36 Sayre S. Content analysis as a tool for consumer research. fournal of Consumer Marketing 1992;9:15-25.

37 Worden JK, Flynn B, Secker-Walker RH. Antismoking campaigns for youth [letter]. $\mathscr{F} A M A 1998 ; 280: 323$

38 Solomon MR. Consumer behavior. Needham Heights, Massachusetts: Allyn and Bacon, 1992.

39 Zollo P. Wise up to teens: insights into marketing and advertising to teenagers. Ithaca, New York: New Strategist Publications, 1999 .

40 Barbeau EM, DeJong W, Brugge DM, et al. Does cigarette print advertising adhere to the Tobacco Institute's voluntary advertising and promotion code? Fournal of $P u b-$ lic Health Policy 1998;19:473-88.

41 Cummings KM, Clarke $\mathrm{H}$. The use of counter-advertising as a tobacco use deterrent and analysis of pending federal tobacco tobiscotion. Washington, DC: Advocacy Institute, 1998. Website: www.advocacy.org/hsap/health.html

42 Chapman S, Fitzgerald B. Brand preference and advertising recall in adolescent smokers: some implications for health promotion. Am f Public Health 1982;72:491-4.

43 Leventhal H, Glynn K, Fleming R. Is the smoking decision an informed choice? $\mathscr{F} A M A 1987 ; 257: 3373-6$.

4 Pinsky I, Silva MTA. A frequency and content analysis of alcohol advertising on Brazilian television. $\mathcal{F}$ Stud Alcohol 1999;60:394-43.

45 Dooley D. Social research methods. Englewood Cliffs, New Jersey: Prentice Hall, 1995.

46 Pierce JP, Gilpin EA, Emery SL. Has the California tobacco control program reduced smoking? fAMA 1998;280:8939.

47 Anon. US Census, 1996. www.census.gov

48 Begay ME, Glantz SA. Question 1 tobacco education expenditures in Massachusetts, USA. Tobacco Control 1997;6:213-8. 
49 Givel MS, Glantz SA. Tobacco industry political power and influence in Florida from 1979 to 1999. San Francisco, CaliMedicine, University of California, San Francisco, 1999. www library.ucs

50 Pechmann CP, Dixon P, Layne N. An assessment of US and Canadian smoking reduction objectives for the year 2000 Am $\mathcal{F}$ Public Health 1998;88:1362-7.

51 Bialous SA, Glantz SA. Arizona's tobacco control initiative illustrates the need for continuing oversight by tobacco control advocates. Tobacco Control 1999;8:141-51.

52 Murray DM, Perry CL, Griffin G, et al. Results from a statewide approach to adolescent tobacco use prevention. Prev Med 1992;21:449-72.

53 Pechmann C. Antismoking advertising and underage smoking. In: Goldberg ME, Gishbein M, Middlestadt SE, eds. Social marketing: theoretical and practical perspectives. Mahwah, New Jersey: Lawrence Erlbaum Associates, 1997:189-216.

54 Anon. Consumer price indexes. 2000. stats.bls.gov/ cpihome.htm

55 Secker-Walker RH, Worden JK, Holland RR, et al. A mass media programme to prevent smoking among adolescents: costs and cost effectiveness. Tobacco Control 1997;6:20712 .

56 Centers for Disease Control. Best practices for comprehensive tobacco control programs-August 1999. National Center for Chronic Disease Prevention and Health Promotion. Atlanta, Georgia: Office on Smoking and Health, 1999.

57 Cook TD, Campbell DT. Quasi-experimentation: design and analysis issues for field settings. Boston, Massachusetts: Houghton Mifflin Company, 1979.

58 California Department of Health Services. Youth smoking trends in California. Tobacco Control Section, 1999. www.dhs.ca.gov/tobacco

59 Smith R. Capturing sensitive data from young people in a household setting. Fournal of the Market Research Society 1996;38:177-83.

60 Fleiss JL. Statistical methods for rates and proportions. New York: Wiley, 1973.

61 Worden JK, Flynn B, Geller BM, et al. Development of a smoking prevention mass media program using diagnostic and formative research. Prev Med 1988;17:531-58.

62 Parpis E. Up in smoke: kicking butt. Adrveek 1997:38:33-8.

3 Balbach ED, Glantz SA. Tobacco control advocates must demand high-quality media campaigns: the California experience. Tobacco Control 1998;7:397-408.

64 Popham WJ, Muthen LK, Potter LD. Effectiveness of the California 1990-1991 tobacco education media campaign. Am f Prev Med 1994;10:319-26.

65 Johnston LD, O'Malley PM, Bachman JG. Cigarette smoking among American teens continues gradual decline. Ann Arbor, Michigan: University of Michigan News and Information Services. www.monitoringthefuture.org
66 Independent Evaluation Consortium. Final report: independent evaluation of the California tobacco control prevention and education program: Wave 1 Data, Maryland: The Gallup Organization, 1998.

67 Siegel M, Biener L. Evaluating the impact of statewide antitobacco campaigns: the Massachusetts and California tobacco control programs. Fournal of Social Issues 1997; 53:147-69.

68 Miller A. Designing an effective counteradvertising campaign-Massachusetts. Cancer 1998;83:2742-5.

69 English B. Sharing a life gone up in smoke. Boston Globe 1998;A01.

70 Gianatasio D. A smoker's brutal fate. Adweek (New England Edition) 1998;35:4.

71 Teicher SA. What's working in the push to discourage smoking. Christian Science Monitor 1999.

72 Anon. Tobacco use among high school students: 1999 Massachusetts youth risk behavior survey results. Boston, Massachusetts: Massachusetts Department of Education, 1999. setts: Massachusetts Department of www.doe.mass.edu

73 Florida Pilot Program on Tobacco Control. Youth demand "truth" from tobacco supporters. 1998. www.newswise.com/ articles/1998

74 Florida Teen Tobacco Summit 2, 1998. www.nosmoking.fsu.edu/summitevent.pdf

75 Bauer U, Johnson T, Pallentino J, et al. Tobacco use among middle and high school students - Florida, 1998 and 1999. Middle and high school students - Florida, 1998 and

76 Minnesota Department of Health. Minnesota tobacco-use prevention initiative 1989-1990: a report to the 1991 legislature. Minneapolis, Minnesota: Section for Nonsmoking and Health, 1991.

77 Mintz JH, Layne N, Ladouceur R. Social advertising and tobacco demand reduction in Canada. In: Goldberg ME, Fishbein M, Middlestadt SE, eds. Social marketing. Mahwah, New Jersey: Lawrence Erlbaum Associates, 1997:217-29.

78 Teinowitz I. After the tobacco settlement. Take the money and run (ads). Washington Post 1998,C1.

79 Biener L, Aseltine RH, Cohen B, et al. Reactions of adult and teenaged smokers to the Massachusetts tobacco tax. Am F Public Health 1998;88:1389-91.

80 Males M. Who us? Stop blaming kids and TV. Progressive 1997;61:25-8.

81 Glantz SA. Preventing tobacco use- the youth access trap. Am f Public Health 1996;86:156-9.

82 Caywood CL. The handbook of strategic public relations and integrated communications. New York: McGraw-Hill, 1997.

83 Sissors JT, Bumba L. Advertising Media Planning. Lincolnwood, Illinois: NTC Business Books, 1989. 